\title{
When No News is Good News - \\ The decrease in Investor Fear after the FOMC announcement
}

ADRIAN FERNANDEZ-PEREZ, BART FRIJNS*, ALIREZA TOURANI-RAD

Department of Finance, Auckland University of Technology, Auckland, New Zealand

* Corresponding author. Department of Finance, Auckland University of Technology, Private Bag 92006, 1142 Auckland, New Zealand. Tel. +64 99219999 (ext. 5706); fax. +64 9921 9940; email bart.frijns@ aut.ac.nz 


\title{
When No News is Good News - The decrease in Investor Fear after the FOMC announcement
}

\begin{abstract}
This paper examines the impact of FOMC announcements on the intraday behavior of the VIX and VIX futures. We find that the VIX and the VIX futures start to decline immediately after the FOMC announcement, and this decline persists for about 45 minutes after the announcement. The VIX declines by about $3 \%$ on announcement days, whereas the nearest term VIX futures contract declines by about $1.40 \%$ around the announcement. We further note that the decline in the VIX and VIX futures is inversely related to the increase in realized volatility around the FOMC announcement. We show that on days with an FOMC announcement, a trading strategy, going short on the VIX futures at the start of the day and closing the position at the end of the same day, yields a return of about $10 \%$ p.a.
\end{abstract}

Keywords: VIX, VIX Futures, FOMC Announcement, Intraday data JEL Codes: G13. 


\section{Introduction}

The reaction of stock markets to the announcements of public information has extensively been studied, mainly with an eye on examining the purported efficiency of these markets. An important source of public information is macroeconomic news, particularly monetary policy decisions in the US, which are revealed after the meeting of the Federal Open Market Committee (FOMC), and are readily available and eagerly anticipated by investors globally. The FOMC news releases have prescheduled announcement dates and times that are known well in advance. The general observation of many studies is that expansionary (contractionary) monetary policy decisions have positive (negative) impacts on stock markets (see, among others, Thorbecke, 1997; Rigobon and Sack, 2004; Bernanke and Kuttner, 2005; Basistha and Kurov, 2008; Kurov, 2010; and D'Amico and Farka, 2011), and that stock market volatility increases at the time of the announcement (see inter allii, Lobo, 2000, 2002; Bomfim, 2003; Farka, 2009; and Chuliá et al., 2010).

While stock market volatility is shown to increase at the time of the FOMC release, several studies have documented that implied volatility decreases at the time of a prescheduled news announcement. In particular, Ederington and Lee (1996) put forward a hypothesis that motivates why implied volatility should decrease after the release of a prescheduled news announcement. They argue that the release of prescheduled news can be seen as the resolution of uncertainty, and since implied volatility is a measure of future volatility, such an announcement reduces the degree of future uncertainty that is left in the market. Indeed, several studies have documented a decrease in implied volatility (typically focusing on the VIX) after the announcement of prescheduled news (e.g. Nikkinen and Sahlström, 2004) and particularly 
the announcement after the FOMC releases (see e.g. Chen and Clements, 2007; Vähämaa and Äijö, 2011; and Gospodinov and Jamali, 2012).

In this paper, we revisit the issue of how implied volatility is affected by the resolution of uncertainty that comes after the FOMC announcement. Our main contribution is that we focus on intraday data to investigate the impact of FOMC announcements on implied volatility. More specifically, we examine the effect of the FOMC announcement on the VIX and on the VIX futures. The existing literature increasingly indicates that stock prices and realized volatility react to the arrival of new information within a very short time period (e.g. Chuliá et al., 2010; Scholtus et al., 2014). By taking advantage of the high frequency in our data, we are able to zoom in and observe how the release of the FOMC decisions affect the VIX and its futures contracts. To the best of our knowledge, our paper is the first to address this issue at an intraday level.

We document several important empirical findings. First, we find support for the hypothesis of Ederington and Lee (1996) on the resolution of uncertainty, where at the time of the FOMC announcement, the VIX drops significantly. In addition, we document that the VIX futures decline after the FOMC announcement as well. The decline in the VIX futures is greater for the nearest term contract, and smaller for the longer term contract. Second, we document that the VIX generally decreases during the trading day, even in the absence of prescheduled news releases. Third, we observe that the decline in the VIX and the VIX futures after the FOMC announcement is not instantaneous but gradual and persists for about 45 minutes after the announcement.This is an important and puzzling finding, as the stock market and realized volatility react immediately to the FOMC announcement (see e.g. Lucca and Moench, 2014). Fourth, the extent of the decline in VIX and VIX futures is strongly negatively related to the 
increase in the realized volatility at the time of the FOMC announcement. Finally, we explore the economic profits that could be obtained from the observed reaction of the VIX futures to the FOMC announcement, and show that a strategy that goes short in the nearest term VIX future at the start of the trading day and closes out at the end of that day generates an average return of 125 basis points per day (or $10 \%$ p.a. based on 8 announcement days per year).

The remainder of this paper is structured as follows. In Section 2 we review the literature. Section 3 discusses the intraday data we employ in this study. Section 4 presents the empirical results of our analysis. Section 5 concludes.

\section{Literature Review}

There is great interest in the examination of the impact of macroeconomic news announcements on asset prices, as the release of this information could represent a large public information shock to the market. Of all macroeconomic news announcement, the announcement made after the meeting of the Federal Open Market Committee (FOMC), seems to have the greatest impact on stock markets (see e.g. Lucca and Moench, 2014). Indeed, many studies have demonstrated the importance of the FOMC meeting and the news announcement following the meeting on asset prices (see e.g. Bernanke and Kuttner, 2005; Basistha and Kurov, 2008; Chuliá et al., 2010; Kurov, 2010; and D'Amico and Farka, 2011). The importance of the news revealed in the FOMC meeting can be even further highlighted by the impact it has on foreign markets (see e.g. Wongswan, 2009; Hausman and Wongswan, 2011; and Lucca and Moench, 2014), and different asset classes (see e.g. Basistha and Kurov, 2014, for the impact of FOMC announcements on energy prices; and Andersen et al., 2007, for the impact on international equity, bond and foreign exchange markets). 
In addition to asset prices, the FOMC announcement is also shown to affect markets' risk factors. Generally, if asset prices react to news, the risk associated with holding such an asset will be higher around announcements. Flannery and Protopapadakis (2002), for instance, contend that macroeconomic news not only affects firms' cash flows but also their risk-adjusted cost of capital. Moreover, Bernanke and Kuttner (2005) attribute a large portion of the positive reaction of markets, due to expansionary monetary policy decisions, to the lessening in risk premiums. Recently, Savor and Wilson (2014) find evidence that the CAPM performs differently on FOMC announcement days (together with employment and inflation news) than non-announcement days. Specifically, beta is positively related to average returns on announcement days but zero or even negative on non-announcement days.

The impact of macroeconomic news on the volatility of stock markets has been investigated in a number of studies, including Lobo (2000, 2002), Bomfim (2003) who use daily data, and Farka (2009) who uses intraday data. These authors, using GARCH models, find macroeconomic news has a significant impact on the conditional volatility of returns. The pattern of conditional volatility observed in these studies has commonly a "tent-shape pattern: abnormally low several hours before announcement, the "calm-before-the-storm effect", increasing significantly during the announcement period, declining steadily while still remaining elevated after the announcement, and continuing to decrease on the day following the policy release" (Farka 2009, p.48).

Andersson (2010), using intraday data, examines stock market volatility reactions to monetary policy decisions, both in the euro zone and the US. She observes a strong increase in volatility at the time of the monetary policy releases by the two central banks, which is more pronounced 
for the US financial markets following Federal Reserve Bank monetary policy decisions. More recently, Lucca and Moench (2014) examine excess returns on the S\&P 500 Index one day prior to the FOMC announcement and find that there is strong evidence of a pre-announcement drift, where excess returns increase by 49 basis points before the announcement; these one-day returns make up about $80 \%$ of annual excess returns. Noteworthy is that on the day before the announcement demonstrates, they observe relatively lower trading volume and lower realized volatility, which is in line with "the calm before the storm argument" of Bomfim (2003) and Farka (2009). These results also hold for international markets and across the cross-section of US stocks.

While aforementioned research concentrates on realized or conditional volatility, there are a number of papers that investigate the impact of the release of monetary policy decisions on implied volatility, especially the VIX, which is the subject of our paper. One of the first studies to evaluate the impact of news announcements on implied volatility is Ederington and Lee (1996) who consider both scheduled and unscheduled news announcement. For scheduled news announcements, they argue that market participants anticipate higher volatilities on days with these announcements, and this higher anticipated volatility is incorporated into the implied volatility prior to the release of the news. Once the news is released, the volatility induced by this information release no longer affects the future volatility of the asset, and hence the implied volatility decreases. For unscheduled news announcements, an increase in implied volatility is expected. Since the release of unscheduled news is not anticipated, the release of such news increases the current volatility, but also increases the expected future volatility, as more information events may be expected to happen. Ederington and Lee (1996) empirically test their hypotheses by examining the implied volatilities of T-bonds, Eurodollars and the Deutsche Mark exchange rate. For scheduled news announcement they focus on ten 
macroeconomic news releases. Overall, they find that on days with scheduled news releases actual volatility tends to increase, whereas implied volatilities decrease. On days with no scheduled news announcements (measured by days without scheduled news announcements but large price movements), implied volatilities tend to increase.

Following the work of Ederington and Lee (1996), various studies have examined the impact of macroeconomic news releases on implied volatility. Using daily data, Nikkinen and Sahlström (2004) examine the relation between the VXO (predecesor of the VIX based on the S\&P100 index options) and several prescheduled announcements (the FOMC meeting, the employment report, the CPI and PPI figures). They find that while all announcements lead to a decrease in the volatility, this decrease is only significant in the case of the FOMC announcement and the employment report. Chen and Clements (2007) examine the relation between the VIX and FOMC announcements for the period 1996-2006, using daily data. They document that the VIX drops significantly on announcement days, but that there are no reaction days before or after the announcement. Vähämaa and Äijö (2011), using daily data for the period 1994-2007, extend the previous two studies by examining the relation between changes in the VIX and target-rate surprises and find a significantly positive relation. When surprises are divided into positive and negative, they find that the positive relation is largely driven by the effect of negative surprises on volatility. Vähämaa and Äijö (2011) further analyze the relation under different economic cycles and note that the relation between FOMC announcements and the VIX is stronger during expantionary periods. Gospodinov and Jamali (2012), using daily data, examine the relation between realized and implied volatility on the S\&P 500 index and FOMC announcements and find that the surprise in these announcements has a positive effect on both realized and implied volatility. 
While various studies have documented the effect of the FOMC announcement on the VIX, little is known about the intraday behaviour of the VIX and its futures on days with the FOMC announcement. In this paper, we address that issue.

\section{Data}

In this section, we describe the intraday data on the VIX and VIX futures and subsequently discuss the data on the FOMC announcements.

\subsection{VIX and VIX futures}

We obtain intraday data for the VIX and VIX futures from the Thomson Reuters Tick History (TRTH) database maintained by SIRCA (Securities Industry Research Centre of Asia-Pacific). The CBOE computes values for the VIX at approximately 15 -second intervals, and hence this is the highest frequency the VIX can be sampled at. In addition, the CBOE maintains the maturity of the VIX equal to 30 days by updating the weights on the near-term and second near-term options every minute during the day. ${ }^{1}$ We therefore sample the VIX at a one-minute frequency following Bailey et al. (2014). Intraday data on the VIX are available from 1 January 1996 onwards, hence our sample runs from that day to 31 December 2013.

In addition to the intraday data on the VIX, we also obtain intraday data on the VIX futures. Given that these futures are traded in real time, we are not restricted to a particular sampling frequency. We thus collect tick-by-tick data time-stamped to the nearest millisecond from the TRTH database. As the VIX futures were introduced on 26 March 2004, we limit the sample

\footnotetext{
${ }^{1}$ See http://www.cboe.com/micro/vix/vixwhite.pdf
} 
for the analysis involving VIX futures to the time period 26 March 2004 to 31 December 2013. We obtain trade and quote data for all VIX futures contracts. The VIX futures contracts have maturities at every month of the year. However, we focus on the first, second, third and fourth nearby contracts. As in Shu and Zhang (2012), we roll to the next nearest maturity contract when the current first nearby contract expires.

In Table 1, we provide some summary statistics on the intraday VIX and VIX futures, where all sampling has been done at a one-minute frequency. For the VIX futures, we compute the midpoint of the bid and ask quotes to mitigate any confounding microstructure issues. The first two columns provide data on the VIX over the periods 1996-2013 and 2004-2013 (the sample period of the VIX futures), respectively. For the data in levels (Panel A), we note that over the period 1996-2013 the VIX was on average 22.44. The VIX has positive skewness and displays excess kurtosis. The first-order autocorrelation of the VIX is close to 1, but an Augmented Dickey-Fuller test rejects the presence of a unit root at the 5\% level. The VIX is slightly lower over the period 2004-2013 with an average of 20.29. Most other properties are similar to the full period, i.e. positive skewness, excess kurtosis, strong persistence, but no unit root.

\section{INSERT TABLE 1 HERE}

For the VIX futures in the next four columns, we observe that the average level of the VIX futures increases as the maturity of the contracts increases. ${ }^{2}$ This result is well documented in the literature (see e.g. Szado, 2009; Shu and Zhang, 2012; and Whaley, 2013 among others), and is due to the term structure of VIX futures prices being on average in contango. All series

\footnotetext{
${ }^{2}$ It should be noted that the underlying value of the VIX futures contract used to be VIX times 10 but on March 26,2007 , the underlying value was changed to be VIX and the futures price became one-tenth of the original value. To be consistent, we divided all prices and quotes in VIX futures before that date by 10 .
} 
are positively skewed and display excess kurtosis. The Augmented Dickey-Fuller statistic demonstrates that we cannot reject the null hypothesis of a unit root being present.

Panel B reports descriptive statistics for the log differences of the series. All series have means of (very close to) zero, which is expected at this high frequency. The VIX in both time periods has slight positive skewness, whereas all the VIX futures contracts display negative skewness. All series display excess kurtosis. The log changes in the VIX reveal negative first-order autocorrelation, which could be attributed to its mean-reverting property. The VIX futures also display negative and significant autocorrelation. The Augmented Dickey-Fuller test suggests that none of the log differences contain unit roots.

\subsection{FOMC Announcements}

During the full sample period 1996-2013, there were a total of 145 scheduled FOMC meetings. However, two of these meetings had their news release before the opening of the market and are thus deleted from the sample. Of the remaining 143 FOMC meetings, 8 meetings had their news releases scheduled at 12.30, 7 at 14.00, and the remaining 128 had their news release at 14.15. Given that the news releases do not occur on the exact scheduled release times, it is important to determine the precise time of the news release when using intraday data. For news releases prior to 2003, we obtain the exact minute of the news release from Lucca and Moench (2014). For the period 2004-2013 (where we have millisecond precision data on the VIX futures), we obtain FOMC announcement times from the Thomson Reuters Global News, available through SIRCA. This database has news releases time stamped to the nearest 
millisecond, and uses the same clock to time stamp news as it uses to time stamp trades and quotes in the VIX futures. $^{3}$

In Figure 1, we plot a histogram of the deviation in announcement times around the scheduled announcement times. As can be seen, there is considerable variation in the actual announcement times, with announcements taking place up to 8 minutes before and 6 minutes after the scheduled announcement time.

\section{INSERT FIGURE 1 HERE}

To capture the surprise component of the news released by the FOMC meeting, we follow the approach proposed by Kuttner (2001) by considering the reaction in the Fed Fund futures. We compute the surprise component by looking at the one-day change in these futures, comparing the closing current-month futures rates of the previous day with the closing rates of the day when the announcement was made. ${ }^{4,5}$ Specifically, we compute the surprise component, $S_{t}$, as

$$
S_{t}=\frac{m}{m-t}\left(F_{t}-F_{t-1}\right)
$$

where $F_{t}$ is the closing current-month futures rate of the Fed Fund futures contract on day $t$, and $m$ is the number of days in the month. Since the Fed Fund futures have expirations at the

\footnotetext{
${ }^{3}$ This database was recently used by Scholtus et al. (2014) in their analysis on the reaction speed of algorithmic traders to the release of macroeconomic news.

${ }^{4}$ The futures rate is defined as 100 minus the contract's price, see Kuttner (2001). We obtain intraday data on the Fed Fund Futures from TRTH.

${ }^{5} \mathrm{We}$ have also computed the change in the Fed Fund futures based on intraday data (open-to-close). This yields results that are almost identical to the ones presented in this paper.
} 
end of each month, we follow the commonly used approach in the literature (see, Bernanke and Kuttner, 2005; Fleming and Piazzesi, 2005; and Chuliá et al., 2010) and employ the change in the next month's futures rate for announcements made within the last seven calendar days of the month. This approach avoids any noise that may be present in at the end of the month in the funds rate.

\section{Empirical Findings}

In this Section, we document the empirical results of our study. We first examine the impact of FOMC announcements on the intraday movements in the VIX and VIX futures. Subsequently, we test whether the surprise in the FOMC announcement has any additional effect on the intraday movements of VIX and VIX futures. We further assess the trading volume around the FOMC announcement. Last, we report the profitability of a trading strategy that aims to exploit the movements in the VIX futures.

\subsection{Reaction in the VIX on FOMC Announcement Days}

In Figure 2, we plot the cumulative change in the VIX on FOMC announcement days versus non-FOMC announcement days. We note that announcement days contain days where the FOMC announcements were at 12.30, 14.00 and 14.15 EST. There are two noteworthy issues to be observed in this graph. First, we observe that on any day (with or without announcements) there is a negative drift in the VIX. On non-announcement days this is close to $-1.25 \%$. Such a negative drift might be due to hedging pressure in the underlying, if one assumes that traders mostly open positions at the start of the trading day and close their positions towards the end 
of the trading day. ${ }^{6}$ Alternatively, the decline in the VIX may reflect the expected information arrival that occurs during the trading day. ${ }^{7}$

On days with FOMC announcements, the decline in the VIX is close to $-3 \%$. On FOMC announcement days, for the part of the day up to the announcement time, the VIX behaves closely to what it behaves like on non-announcement days. However, at the time of the announcement, we observe a marked decline in the VIX. This negative reaction is in line with the expectation of Ederington and Lee (1996), who document a decline in implied volatility of stock options and is in line with the empirical evidence in Nikkinen and Sahlström (2004), Chen and Clements (2007), and Vähämaa and Äijö (2011), who examine the impact of news announcement on the VIX at daily frequencies. What we observe in our data is that the decline in the VIX is not instantaneous, and that there is a post-FOMC announcement drift in the VIX.

\section{INSERT FIGURE 2 HERE}

To investigate the effect of FOMC announcements on movements in the VIX, we zoom- in on the period surrounding the FOMC announcement times. We take all the FOMC announcements that happened during the trading day, and take the exact announcement time (rounded down to the nearest minute as in Lucca and Moench, 2014) as our event time $(t=0)$. We then consider the minute-by-minute movements in the VIX and the VIX futures around this announcement time from 15 minutes before the announcement to 60 minutes after the announcement.

\footnotetext{
${ }^{6}$ This argument could fit with the excess demand explanation of Harvey and Whaley (1992), who demonstrate that the implied volatility of the S\&P100 index options tend to be higher on Mondays and lower on Fridays. They attribute this to excess buying of index options on Mondays and selling on Fridays.

${ }^{7}$ Another explanation may be that the VIX declines due to other prescheduled news announcements that are not included in this study. However, we have collected data on 25 other major macroeconomic news announcements (such as GDP, unemployment, etc.) and note that the VIX also declines on days without any of these major announcements.
} 
In Figure 3, we present the cumulative movement in the VIX and the four nearest-term VIX futures. The bold line in this figure shows the cumulative movement in the VIX around 14.15 on non-FOMC announcement days. As can be seen, on non-announcement days, there is virtually no change in the VIX around this time. On FOMC announcement days, we observe a negative reaction in the VIX and in all four futures contracts. This reaction is strongest in the VIX, which decreases by more than $2 \%$ in the window around the FOMC announcement. All the VIX futures contracts also decline following the FOMC announcement, with the near-term contract reacting most (declining by nearly $1.5 \%$ in the period of 15 minutes before the announcement to 60 minutes after the announcement), followed by the second, third and fourth nearby futures contracts, respectively.

\section{INSERT FIGURE 3 HERE}

Although the decline in the VIX can be attributed to the resolution of uncertainty that comes with the FOMC announcement, the reaction in the VIX futures to the FOMC announcement suggest that there may be an economically profitable trading strategy that could be implemented around the FOMC announcement. This pattern in the reactions of VIX futures with different maturities (where the near-term contract reacts more than the longer-term contracts) can be explained with the hypotheses poised by Ederington and Lee (1996), as the reduction in uncertainty that comes with the FOMC announcement has a greater impact on the implied volatility of nearby contracts than of longer-term contracts. 
The second important observation is that the drop in the VIX and its futures is not instantaneous, but the VIX and the VIX futures observe a post-FOMC announcement drift lasting for about 45 minutes. This prolonged and sluggish reaction is puzzling, as the information revealed in the FOMC announcement is generally incorporated into the market very quickly, for example, Lucca and Moench (2014) show that there is no drift in the stock market index after the FOMC announcement. In addition, following the argument of Ederington and Lee (1996), the implied volatility should decrease by the amount of uncertainty that gets resolved through the FOMC announcement. Given that that resolution is instantaneous a prolonged decrease in VIX and VIX futures is a remarkable phenomenon.

To determine how promptly the VIX futures respond to the FOMC announcement, and whether there is a pre-FOMC announcement drift, we zoom-in even further and use the exact announcement time and sample the VIX futures at a decisecond frequency centered on the announcement time.

\section{INSERT FIGURE 4 HERE}

We plot the cumulative movements in the VIX futures one minute before and one minute after the exact announcement time in Figure 4. As can be seen from this figure, there is no observable trend in the VIX futures prior to the FOMC announcement. However, all four futures contracts start to decline in value immediately following the exact announcement time onwards. We do not observe a large initial reaction to the FOMC announcement, but from the announcement times onwards all contracts display a gradual negative drift. 
The results presented in these three figures demonstrate a significant reaction in the VIX and VIX futures around the FOMC announcement time, where there appears to be a negative drift in the VIX and the VIX futures immediately following the announcement. To determine whether these reactions are statistically significant, we conduct t-tests on the difference in means and Wilcoxon rank tests on the difference in medians for the different contracts and for different windows.

In Table 2, we report the results for these tests for the different contracts and time intervals. Panel A reports the difference in the reaction of the VIX and the VIX futures on FOMC announcement days versus non-FOMC announcement days in the period from open (9.30) to close (16.15). We observe that for all contracts there is a significantly more negative reaction in the VIX and the VIX futures on FOMC announcement days compared with nonannouncement days. The statistical significance appears to be stronger for the VIX futures than for the VIX itself.

Panel $\mathrm{B}$ focuses on the window ranging from 15 minutes before the FOMC announcement to 60 minutes after the announcement. Again, we observe significant reactions in all contracts. We also note that the t-statistics increase considerably, compared with Panel A, suggesting stronger evidence of a reaction at the intraday level.

\section{INSERT TABLE 2 HERE}

In Panels $\mathrm{C}$ and $\mathrm{D}$, we examine whether the reaction is observed in the pre- or postannouncement periods. Panel $\mathrm{C}$ shows that the evidence on a reaction prior to the announcement is weak. Based on the t-test, there is some evidence of a reaction in the VIX 
prior to the announcement, and we observe a significant reaction in two of the futures contracts. According to the Wilcoxon test there is no significant reaction in the VIX, but there is in two of the futures contracts. Panel D shows the reaction in the hour after the announcement. We observe a highly significant negative reaction in all contracts during this hour.

Finally, we separate the hour following the FOMC announcement into four quarters, and report results in Panels E to H. Overall, we note that there are significant reactions in the first, second, and third quarters, but no significant reactions in the fourth quarter. These findings suggest that the VIX and the VIX futures take about 45 minutes to react to the FOMC announcement.

To take a closer look at the properties of the VIX and the VIX futures around FOMC announcement times, we report distributional properties of these contracts in Table 3 . This table reports the properties of the data in the window from 15 minutes before the announcement to 60 minutes after the announcement. As can be seen, in all contracts, the volatility in the VIX is higher on days with FOMC announcements than on days with no announcements. We also note that, for all contracts, skewness is negative during the FOMC announcement period, but is positive during the same period on non-announcement days. There is also a considerable difference in kurtosis during the announcement period on FOMC announcement days versus non-announcement days, where kurtosis is lower on FOMC announcement days.

\section{INSERT TABLE 3 HERE}

As observed by e.g. Chuliá et al. (2010), realized volatilities tend to increase around FOMC news announcements and as we have demonstrated implied volatilities tend to decrease. We next wish to examine whether there is a relation between the magnitude of increase in realized 
volatility and the decrease in implied volatility. Such a relation could be expected in the framework of Ederington and Lee (1996), as implied volatility should decrease by the magnitude of uncertainty that gets resolved at the time of the FOMC announcement. The increase in spot volatility, i.e. realized volatility around the FOMC announcement, may be a proxy for this magnitude. We again consider the period ranging from 15 minutes before the FOMC announcement to 60 minutes after the FOMC announcement. We compute the realized volatility based on 1-minute frequency returns on the S\&P 500 Index ${ }^{8}$ and compute realized volatility $(R V)$ as

$$
R V=\sqrt{\sum_{t=t_{0}-15}^{t_{0}+60} r_{t}^{2}},
$$

where $r_{t}$ are minute-by-minute returns on the S\&P 500 Index and $t_{0}$ is the time of announcement rounded down to the nearest minute. We then conduct the following regression

$$
\Delta \triangle V I X_{N}=\alpha+\beta \Delta R V_{N}+\varepsilon_{N},
$$

where $\Delta \Delta V I X_{N}$ is the difference in the VIX or any of the VIX futures during the $(15,+60)$ window for announcement days $N$ and the average of days without FOMC announcements around 14.15, and $\Delta R V_{N}$ is the difference in realized volatility for announcement day $N$ and the average of days without FOMC announcements around 14.15.

We present the results for this regression in Table 4. The first and second rows in this table present the results for the VIX. As can be seen, the intercepts are negative and statistically significant, confirming our earlier finding that there is a significant decline in the VIX on

${ }^{8}$ We obtain intraday data on the S\&P500 from TRTH. 
FOMC announcement days versus non-announcement days. In addition, we observe a significant negative coefficient on $\Delta R V_{N}$. These findings suggest that the magnitude of the increase in realized volatility around the FOMC announcement relates to the decline in the VIX, and confirm the postulation that the VIX declines by the amount of uncertainty that gets resolved at the time of the FOMC announcement.

\section{INSERT TABLE 4 HERE}

For the VIX futures, the results are as expected, for all contracts we observe a negative and significant intercept, confirming our earlier finding that the VIX futures decline in the period around FOMC announcements. We also note that these coefficients become smaller in magnitude as the maturity of the contract increases, which confirms the findings that the nearterm contracts are more affected by the FOMC announcement. In line with the results for the VIX, we note that the impact of the change in realized volatility over the period surrounding the FOMC announcement is negatively and significantly related to the change in the VIX futures, where again the coefficients decrease in magnitude as the maturity of the contract increases.

\subsection{Asymmetric reaction of VIX to news}

So far, we have considered the impact of FOMC announcements on the VIX and VIX futures. We next aim to consider the impact of the surprise in the FOMC announcement on the VIX and VIX futures. If the announcement of a policy decision contains a surprise element, that has previously not been anticipated and incorporated into asset prices, could lead to higher realized volatility. Following Ederington and Lee's (1996) arguments, we could expect that a surprise in the FOMC announcement would also cause the VIX to increase. Hence, in combination with 
the fact that FOMC announcements are prescheduled, we would expect that on days with news surprises, the VIX would decrease less than on days without surprises. In addition, several studies (Black, 1976. French et al., 1987, Nelson, 1987, and Bomfin, 2003) suggest that reactions to FOMC announcements are asymmetric, where positive interest rate surprises (funds rate higher than expected) have a much stronger impact on volatility than negatives news. Indeed, Vähämaa and Äijö (2011) divide surprises into positive and negative, and find that the effect of negative surprises on implied volatility is stronger than that of positive surprises. We therefore conduct the following regression,

$$
\Delta V I X_{N}=\alpha_{0}+\left(\alpha_{1}+\beta_{1} S_{N}\right) D_{N}^{+}+\left(\alpha_{2}+\beta_{2} S_{N}\right) D_{N}^{-}+\varepsilon_{N}
$$

where $\triangle V I X_{N}$ is log change in the VIX over the window from 15 minutes before the announcement to 60 minutes after the announcement on FOMC announcement days, $D_{N}^{+}$is a dummy variable that is equal to one for days with positive changes in the Fed Fund futures, and $D_{N}^{-}$is a dummy variable that is equal to one for days with negative changes in the Fed Fund futures. The coefficients $\alpha_{0}$ captures the impact of days without surprises. The coefficients $\alpha_{1}$ and $\alpha_{2}$ capture the effect of the presence of a positive and negative surprise, respectively; and $\beta_{1}$, and $\beta_{2}$ capture the impact of the magnitude of the positive and negative surprise, respectively.

The results for this regression are presented in Table 5. The first column of this table shows the results for the VIX over the full sample period. We find that when there is no surprise in the FOMC announcement the VIX decreases significantly, the coefficient for $\alpha_{0}$ is $-1.37 \%$. We note that $\alpha_{1}$ is statistically insignificant suggesting that there is no additional impact on the VIX from positive surprises. In contrast, $\alpha_{2}$ is negative and significant, suggesting there is an 
additional decrease in VIX from negative surprises. Of the coefficients that measure the magnitude of the surprise, we note that both $\beta_{1}$ and $\beta_{2}$ are significant with negative and positive signs, respectively, suggesting that the larger the shock (either positive or negative), the more negative the change in the VIX. When we focus on the VIX over the period 2004-2013, we note that the intercept is still significantly negative. However, only $\beta_{2}$ is positive and significant, suggesting that when there is a negative surprise in the FOMC announcement, the VIX tends to decrease. Overall, the results suggest that there may be some impact of the magnitude of surprises on the change in the VIX around the FOMC announcement time.

\section{INSERT TABLE 5 HERE}

For the VIX futures, the results are straightforward, there is a negative reaction on days with FOMC announcement, but whether there is a positive or negative surprise in the announcement (and its magnitude) there seems to have no impact on the change in the VIX.

\subsection{Trading Volume in the VIX Futures}

Our results so far demonstrate a clear reaction of the VIX futures immediately after the FOMC announcement. We next examine whether there is a similar response in the trading volume of the VIX futures. In Figure 5, we plot the 30-second rolling average of the number of VIX futures contracts traded for the 4 nearest-term futures contracts over the window from 5 minutes before the announcement to 5 minutes after, where we use the exact announcement time. From this figure, we can observe a nearly immediate uptake in trading volume in the futures of all maturities, which peaks about 40 seconds after the announcement time. We can also observe that volume remains elevated relative to the volume before the announcement for the 5-minute period after the announcement. The uptake in trading volume is largest for the 
nearest term future contract, followed by the second, third and fourth contract, respectively. Interestingly, we observe no increased trading volume prior to the FOMC announcement.

\section{INSERT FIGURE 5 HERE}

In Table 6, we present the results for the statistical tests of whether the volume in the VIX futures increases significantly in the period after the announcement. The first two columns report the mean and median trading volume around 14.15 for non-FOMC announcement days. As can be seen, there is no significant change in the trading volume on non-FOMC announcement days. For FOMC announcement days, we observe that there is a significant increase in the volume, where both the mean and the median increase significantly relative to the post-announcement period for all four futures contracts examined.

\section{INSERT TABLE 6 HERE}

\subsection{Trading Strategy}

The results documented in this study suggest that there may be a potential trading strategy. In this section, we explore the profitability of such a trading strategy. Specifically, we consider the strategy where we take a short position at the start of the trading day at 9.35 EST, by selling the VIX futures contract at the prevailing bid price, and close the position at 15.30 EST by taking an offsetting position at the prevailing ask price. ${ }^{9}$ Trading at the actual prevailing quotes ensures that we incorporate the costs of the bid-ask spread into our trading strategy. In addition,

\footnotetext{
${ }^{9} \mathrm{We}$ open the position at 9.35 and close at 15.30 to stay clear of the open and close of the market, as these periods are often characterized by high volatility and wider bid-ask spreads.
} 
we take a transaction cost of $0.10 \%$ per trade into account. ${ }^{10}$ In Table 7 we present the results for this trading strategy.

\section{INSERT TABLE 7 HERE}

In Panel A, we present the results for the full sample starting in March 2004 to December 2013. We report the daily performance of the strategy on non-announcement days and days with FOMC announcements. On non-announcement days, we observe that the strategy results in a loss. This is predominantly due to the trading costs. For FOMC announcement day, we note that the average return is positive for the first three nearby contracts, and negative for the fourth nearby contract. However, the average return is only significant for the first and second nearby contracts. The first nearby contract offers a daily return of 125 basis points, whereas the second nearby contract offers a positive return of 56 basis points. Based on the 8 announcements occurring per year this strategy would result in an annual return of $10 \%$ and $4.48 \%$, on average, for the first and second nearby contracts, respectively. The strategy for the first nearby contract is slightly more volatile than the strategy for the second nearby contract, and has a higher $99 \%$ VaR. The strategy involving the first nearby contract offers positive returns on $67 \%$ of the days when the strategy is implemented, versus $59 \%$ of days with positive returns for the second nearby contract. The first nearby contract produces a daily Sharpe ratio of 0.37 , which, based on the 8 announcements per year, yields an annual Sharpe ratio of 1.04. The second nearby contract has a daily Sharpe ratio of 0.22 , translating into an annual Sharpe ratio of 0.62 . Finally, the Omega ratio ${ }^{11}$ for both first and second nearby contracts are both well above one, suggesting

\footnotetext{
${ }^{10} \mathrm{We}$ base transaction costs on a reasonable cost assumed by market participants, see http://volatilitymadesimple.com/backtest-comparing-the-vix-index-to-front-month-vix-futures/

${ }^{11}$ The Omega ratio provides an indication of the probability of achieving a return greater than a specific threshold (in our case the threshold is equal to zero). A ratio of one implies that the probability of exceeding the threshold is equal to the probability of falling short. A ratio greater than one implies the probability of exceeding the threshold is greater than the probability of falling short, and vice versa.
} 
that there is a considerably higher probability of positive returns than negative returns in this strategy. On the whole, the results presented above suggest that the strategies that involve the first and second nearby contracts are highly profitable.

To assess whether the profitability of the trading strategy is affected by the sample period or by liquidity, we also compute the profitability of the trading strategy from 2008 onwards. Since 2008, the liquidity in the VIX futures contracts has increased substantially. ${ }^{12}$ In Panel B, we report statistics on the performance of this strategy over the shorter time period. Overall, the results on the trading strategy are in line with the results presented in Panel A, suggesting that our trading strategy is robust over these time periods. On the first nearby contract we find a profitability of 114 basis points per day (9.12\% p.a.), with a daily Sharpe ratio of 0.40 (1.13 per year). For the second nearby contract the profitability is 65 basis points per day $(5.20 \%$ p.a.), with a Sharpe ratio of 0.28 (0.79 per year),

\section{Conclusion}

Using intraday data, we examine the impact of FOMC announcements on the VIX and VIX futures. We document several important empirical findings. First, we find that at the time of the announcement the VIX drops significantly, confirming the hypothesis put forth originally by Ederington and Lee (1996). We show that not only the VIX decreases after a FOMC announcement, but this decline is also observed in the VIX futures. Second, we document that the VIX generally decreases during the trading day even in the absence of prescheduled news releases, and attribute this to either demand pressures in the underlying index option market,

\footnotetext{
${ }^{12}$ Average daily volume and daily total number of quotes increased by a factor of 27 and 70 , respectively, in the period 2008-2013 compared with 2004-2007,
} 
or the market's expectation of information arrival during the trading day. Third, we observe that the decline in the VIX and the VIX futures after the FOMC announcement is not instantaneous but gradual, and seems to persist for about 45 minutes after the announcement. This finding puts forth an interesting puzzle, as the information revealed in the FOMC announcement is generally incorporated into the market very quickly (see e.g. Lucca and Moench, 2014). Fourth, the extent of the decline in VIX and VIX futures is strongly negatively related to the increase in the realized volatility at the time of the FOMC announcement. Finally, we explore the potential economic profits that could be extracted from the observed reaction of the VIX futures to the FOMC announcement, and show that a strategy that goes short in the nearest term VIX future at the start of a trading day and closes out at the end of that day generates an average return of 125 basis points per day (or $10 \%$ p.a. based on 8 announcement days per year). 


\section{References}

Andersen, T. G., Bollerslev, T., Diebold, F. X., and Vega, C. (2007). Real-time price discovery in global stock, bond and foreign exchange markets. Journal of International Economics 73, 251-277.

Andersson, M. (2010). Using intraday data to gauge financial market responses to Federal Reserve and ECB monetary policy decisions. International Journal of Central Banking 21, $117-146$

Bailey, W., Zheng, L. and Zhou, Y. (2012). What makes the VIX tick? HKIMR Working Paper No. 22/2012.

Basistha, A. and Kurov, A. (2014). The impact of monetary policy surprises on energy prices. Journal of Futures Markets, forthcoming.

Bernanke, B. S., and Kuttner, K. N. (2005). What explains the stock market's reaction to federal reserve policy? Journal of Finance 60, 1221-1257.

Bomfim, A. N. (2003) Pre-announcement effects, news effects, and volatility: Monetary policy and the stock market. Journal of Banking and Finance 27, 133-151.

Chen, E., and Clements, A. (2007). S\&P 500 implied volatility and monetary policy announcements. Finance Research Letters 4, 227-232.

Chuliá, H., Martens, M., and van Dijk. D. (2010). Asymmetric effects of federal funds target rate changes on S\&P100 stock returns, volatilities and correlations. Journal of Banking and Finance 34, 834-839.

D'Amico, S., and Farka, M. (2011). The Fed and the stock market: An identification based on intraday futures data. Journal of Business and Economic Statistics 29, 126-137.

Ederington, L. H., and Lee, J. H. (1996). The creation and resolution of market uncertainty: the impact of information releases on implied volatility. Journal of Financial and Quantitative Analysis 31, 513-539.

Farka, M. (2009). The effect of monetary policy shocks on stock prices accounting for endogeneity and omitted variable biases. Review of Financial Economics 18, 47-55.

Flannery, M.J., and Protopapadakis, A. A. (2002). Macroeconomic factors do influence aggregate stock returns. Review of Financial Studies 15, 751-782.

Fleming, M.J., and Piazzesi, M., (2005). Monetary policy tick-by-tick. Working Paper, Federal Reserve Bank of New York.

Gospodinov, N., and Jamali, I. (2012). The effects of Federal funds rate surprises on S\&P500 volatility and volatility risk premium. Journal of Empirical Finance 19, 497-510.

Harvey, C. R., and Whaley, R. E. (1992). Market volatility prediction and the efficiency of the S\&P 100 index option market. Journal of Financial Economics 31, 43-73. 
Hausman, J. and Wongswan, J. (2011). Global asset prices and FOMC announcements. Journal of International Money and Finance 30, 547-571.

Kurov, A., (2010). Investor sentiment and the stock market's reaction to monetary policy. Journal of Banking and Finance 34, 139-149.

Kuttner, K. N, (2001). Monetary policy surprises and interest rates: Evidence from the Fed Funds futures market. Journal of Monetary Economics 47, 523-544.

Lobo, B.J. (2000). Asymmetric effects of interest rate changes on stock prices. Financial Review 35, 125-144.

Lobo, B.J. (2002). Interest rate surprises and stock prices. Financial Review 37, 73-92.

Lucca, D. O., and Moench, E. (2014). The pre-FOMC announcement drift. Journal of Finance, forthcoming.

Nikkinen, J., and Sahlström, P. (2004). Impact of the federal open market committee's meetings and scheduled macroeconomic news on stock market uncertainty. International Review of Financial Analysis 13, 1-12.

Rigobon, R., and Sack, B. (2004). The impact of monetary policy on asset prices. Journal of Monetary Economics 51, 1553-1575.

Savor, P., and Wilson, M. (2014). Asset pricing: A tale of two days. Journal of Financial Economics 113, 171-201.

Scholtus, M., van Dijk, D., and Frijns, B. (2014). Speed, algorithmic trading, and market quality around macroeconomic news announcements. Journal of Banking \& Finance 38, 89105.

Shu, J., and Zhang, J. (2012). Causality in the VIX futures market. Journal of Futures Markets $32,24-46$.

Szado, E. (2009). VIX futures and options: A case study of portfolio diversification, Journal of Alternative Investments 12, 68-85.

Thorbecke, W. (1997). On stock market returns and monetary policy. Journal of Finance 52, 635-654.

Vähämaa, S., and Äijö, J. (2011). The Fed's policy decision and implied volatility. Journal of Futures Markets 31, 995-1009.

Whaley, R. E. (2013). Volatility trading: At what cost? Working paper, Owen Graduate School of Management, Vanderbilt University.

Wongswan, J. (2009). The response of global equity indexes to U.S. monetary policy announcements. Journal of International Money and Finance 28, 344-365. 
Table 1. Descriptive statistics on the VIX and VIX Futures

\begin{tabular}{|c|c|c|c|c|c|c|}
\hline & \multicolumn{2}{|c|}{ VIX Index } & \multicolumn{4}{|c|}{ VIX Futures } \\
\hline & 1996-2013 & 2004-2013 & $1 \mathrm{st}$ & 2nd & $3 \mathrm{rd}$ & 4th \\
\hline \multicolumn{7}{|c|}{ Panel A: Levels } \\
\hline Mean & 22.44 & 20.29 & 20.74 & 21.55 & 22.14 & 22.80 \\
\hline St. Dev. & 8.99 & 10.01 & 9.14 & 8.16 & 7.47 & 6.98 \\
\hline Skewness & 1.66 & 2.29 & 1.96 & 1.56 & 1.33 & 1.06 \\
\hline Kurtosis & 7.78 & 9.73 & 7.69 & 5.93 & 5.14 & 4.11 \\
\hline$\rho(1)$ & $0.9997 * * *$ & $0.9999 * * *$ & $1.0000 * * *$ & $1.0000 * * *$ & $1.0000 * * *$ & $0.9999 * * *$ \\
\hline$A D F$ & $-2.54 * *$ & $-2.02 * *$ & -1.42 & -1.02 & -0.86 & -0.78 \\
\hline$J B$ Stat & $2527392 * * *$ & $2748772 * * *$ & $1546293 * * *$ & $757848 * * *$ & $480915^{* * * *}$ & $223694 * * *$ \\
\hline \multicolumn{7}{|c|}{ Panel B: Log Differences } \\
\hline Mean & 0.0000 & 0.0000 & 0.0000 & 0.0000 & 0.0000 & 0.0000 \\
\hline St. Dev. & 0.0035 & 0.0024 & 0.0017 & 0.0014 & 0.0012 & 0.0011 \\
\hline Skewness & 0.1123 & 0.1995 & -0.2659 & -1.0235 & -0.8686 & -0.3730 \\
\hline Kurtosis & 48.65 & 156.10 & 28.94 & 91.18 & 348.63 & 458.10 \\
\hline$\rho(1)$ & $-0.1526 * * *$ & $-0.0359 * * *$ & $-0.0596 * * *$ & $-0.0782 * * *$ & $-0.0741 * * *$ & $-0.0730 * * *$ \\
\hline$A D F$ & $-241.34 * * *$ & $-166.76 * * *$ & $-170.66^{* * * *}$ & $-174.85 * * *$ & $-179.42 * * *$ & $-176.57 * * *$ \\
\hline$J B$ Stat $\left(x 10^{6}\right)$ & $155.01 * * *$ & $969.29 * * *$ & $27.837 * * *$ & $321.89 * * *$ & $4915.2 * *$ & $8096.2 * * *$ \\
\hline
\end{tabular}

Note: This Table presents descriptive statistics on the VIX and the VIX Futures. Panel A reports descriptive statistics for the levels; Panel B reports the results for the log differences. We report the mean, standard deviation, skewness and kurtosis. $\rho(1)$ represents the first-order autocorrelation and ADF is the Augmented Dickey-Fuller statistic . The JB statistic is the Jarque-Bera statistic. We indicate significance at the $10 \%$, $5 \%$, and $1 \%$ level by *, $* *$, and $* * *$, respectively. 
Table 2. Reaction of VIX and VIX futures around FOMC Announcements

\begin{tabular}{|c|c|c|c|c|c|c|c|c|c|c|c|c|}
\hline & \multicolumn{4}{|c|}{ VIX } & \multicolumn{8}{|c|}{ VIX Futures } \\
\hline & \multicolumn{2}{|c|}{ 1996-2013 } & \multicolumn{2}{|c|}{$2004-2013$} & \multicolumn{2}{|c|}{$1 \mathrm{st}$} & \multicolumn{2}{|c|}{ 2nd } & \multicolumn{2}{|c|}{$3 \mathrm{rd}$} & \multicolumn{2}{|c|}{ 4th } \\
\hline \multicolumn{13}{|c|}{ Panel A: Open to Close } \\
\hline & Diff. & Stat & Diff. & Stat & Diff. & Stat & Diff. & Stat & Diff. & Stat & Diff. & Stat \\
\hline Mean & -0.0183 & $-3.14 * * *$ & -0.0189 & $-2.30 * *$ & -0.0189 & $-4.48 * * *$ & -0.0136 & $-4.52 * * *$ & -0.0109 & $-4.39 * * *$ & -0.0088 & $-3.94 * * *$ \\
\hline Median & -0.0132 & $-4.19 * * *$ & -0.0053 & $-2.40 * *$ & -0.0150 & $-4.07 * * *$ & -0.0087 & $-3.76 * * *$ & -0.0076 & $-3.82 * * *$ & -0.0071 & $-3.37 * * *$ \\
\hline \multicolumn{13}{|c|}{ Panel B: [-15:+60] minutes around news time } \\
\hline Mean & -0.0194 & $-9.77 * * *$ & -0.0229 & $-8.46 * * *$ & -0.0136 & $-8.43 * * *$ & -0.0081 & $-6.94 * * *$ & -0.0064 & $-6.64 * * *$ & -0.0050 & $-6.08 * * *$ \\
\hline Median & -0.0141 & $-6.98 * * *$ & -0.0147 & $-5.61 * * *$ & -0.0098 & $-4.96 * * *$ & -0.0031 & $-3.80 * * *$ & -0.0030 & $-4.02 * * *$ & -0.0020 & $-3.45 * * *$ \\
\hline \multicolumn{13}{|c|}{ Panel C: [-15:0] minutes around news time } \\
\hline Mean & -0.0017 & $-2.06 * *$ & -0.0027 & $-2.60 * * *$ & -0.0012 & $-1.92 *$ & -0.0004 & -0.96 & -0.0008 & $-2.23 * *$ & -0.0007 & $-2.09 * *$ \\
\hline Median & -0.0008 & -1.32 & -0.0007 & -1.05 & -0.0004 & $-2.14 * *$ & 0.0000 & -0.55 & 0.0000 & $-2.70 * * *$ & 0.0000 & -1.56 \\
\hline \multicolumn{13}{|c|}{ Panel D: [0:+60] minutes around news time } \\
\hline Mean & -0.0177 & $-9.71 * * *$ & -0.0202 & $-8.39 * * *$ & -0.0124 & $-8.60 * * *$ & -0.0077 & $-7.23 * * *$ & -0.0055 & $-6.33 * * *$ & -0.0043 & $-5.65 * * *$ \\
\hline Median & -0.0137 & $-6.89 * * *$ & -0.0126 & $-5.29 * * *$ & -0.0083 & $-5.02 * * *$ & -0.0036 & $-3.62 * * *$ & -0.0044 & $-3.79 * * *$ & -0.0021 & $-3.10 * * *$ \\
\hline \multicolumn{13}{|c|}{ Panel E: $[0:+15]$ minutes around news time } \\
\hline Mean & -0.0067 & $-3.61 * * *$ & -0.0071 & $-6.40 * * *$ & -0.0052 & $-7.94 * * *$ & -0.0036 & $-7.42 * * *$ & -0.0025 & $-6.33 * * *$ & -0.0025 & $-6.87 * * *$ \\
\hline Median & -0.0039 & $-3.61 * * *$ & -0.0048 & $-4.20 * * *$ & -0.0029 & $-4.26 * * *$ & -0.0021 & $-3.42 * * *$ & -0.0018 & $-4.27 * * *$ & -0.0011 & $-4.06 * * *$ \\
\hline \multicolumn{13}{|c|}{ Panel $F:[+15:+30]$ minutes around news time } \\
\hline Mean & -0.0030 & $-1.65^{*}$ & -0.0061 & $-5.69 * * *$ & -0.0027 & $-4.18 * * *$ & -0.0015 & $-2.83 * * *$ & -0.0008 & $-2.04 * *$ & -0.0001 & -0.27 \\
\hline Median & -0.0022 & $-2.58 * * *$ & -0.0032 & $-3.33 * * *$ & -0.0027 & $-3.25 * * *$ & -0.0009 & $-2.09 * *$ & -0.0004 & $-1.98 * *$ & -0.0003 & -1.08 \\
\hline \multicolumn{13}{|c|}{ Panel G: [+30:+45] minutes around news time } \\
\hline Mean & -0.0065 & $-7.53 * * *$ & -0.0067 & $-6.70 * * *$ & -0.0038 & $-6.14 * * *$ & -0.0026 & $-5.27 * * *$ & -0.0015 & $-3.58 * * *$ & -0.0015 & $-4.33 * * *$ \\
\hline Median & -0.0040 & $-5.30 * * *$ & -0.0040 & $-3.94 * * *$ & -0.0012 & $-2.95 * * *$ & 0.0000 & $-2.14 * *$ & 0.0000 & -1.03 & -0.0005 & $-2.30 * *$ \\
\hline \multicolumn{13}{|c|}{ Panel H: $[+45:+60]$ minutes around news time } \\
\hline Mean & -0.0015 & -1.50 & -0.0003 & -0.26 & -0.0007 & -0.90 & 0.0000 & -0.09 & -0.0007 & -1.47 & -0.0001 & -0.37 \\
\hline Median & -0.0014 & -0.87 & 0.0004 & 0.10 & 0.0003 & 0.93 & 0.0000 & 0.70 & 0.0000 & -0.61 & 0.0000 & -0.21 \\
\hline
\end{tabular}

Note: This table reports the differences in performance of the VIX and VIX Futures on FOMC announcement days versus non-announcement days. The different panels in this table consider different windows around the announcement. We compute the difference in the mean and conduct a t-test for difference in means. We also compute medians and compute a Wilcoxon rank test to assess the significance of the difference in the medians. We indicate significance at the $10 \%, 5 \%$, and $1 \%$ level by $*, * *$, and $* * *$, respectively.

\section{Table 3. Distributional Properties around FOMC Announcements [-15:+60] window}




\begin{tabular}{|c|c|c|c|c|c|c|c|c|c|c|c|c|}
\hline & \multicolumn{4}{|c|}{ VIX Index } & \multicolumn{8}{|c|}{ VIX Futures } \\
\hline & \multicolumn{2}{|c|}{ 1996-2013 } & \multicolumn{2}{|c|}{ 2004-2013 } & \multicolumn{2}{|c|}{$1 \mathrm{st}$} & \multicolumn{2}{|c|}{ 2nd } & \multicolumn{2}{|l|}{$3 \mathrm{rd}$} & \multicolumn{2}{|l|}{ 4th } \\
\hline & Non-ann. & FOMC & Non-ann. & FOMC & Non-ann. & FOMC & Non-ann. & FOMC & Non-ann. & FOMC & Non-ann. & FOMC \\
\hline Mean & -0.0008 & -0.0202 & 0.0004 & -0.0225 & -0.0002 & -0.0138 & 0.0000 & -0.0081 & 0.0000 & -0.0064 & 0.0001 & -0.0050 \\
\hline $\begin{array}{l}\text { St. Dev. } \\
\text { Skewnes }\end{array}$ & 0.0225 & 0.0404 & 0.0225 & 0.0452 & 0.0133 & 0.0289 & 0.0097 & 0.0198 & 0.0080 & 0.0151 & 0.0068 & 0.0128 \\
\hline$s$ & 0.5417 & -0.9469 & 1.0558 & -0.7995 & 0.7495 & -1.6284 & 0.5305 & -1.4163 & 0.3382 & -1.0409 & 0.3336 & -1.1537 \\
\hline Kurtosis & $\begin{array}{r}14.6050 \\
25075.52 * *\end{array}$ & $\begin{array}{r}5.3267 \\
53.25^{* *}\end{array}$ & $\begin{array}{r}19.8517 \\
29480.73 * *\end{array}$ & $\begin{array}{r}4.6588 \\
17.25^{* *}\end{array}$ & $\begin{array}{r}11.8206 \\
8171.77^{* * *}\end{array}$ & $\begin{array}{r}8.1573 \\
120.91^{* *}\end{array}$ & $\begin{array}{r}12.4905 \\
9317.10^{* * *}\end{array}$ & $\begin{array}{r}5.7872 \\
51.32 * *\end{array}$ & $\begin{array}{r}10.8530 \\
6313.65 * *\end{array}$ & $\begin{array}{r}4.4231 \\
20.40^{* *}\end{array}$ & $\begin{array}{r}9.7958 \\
4505.40 * *\end{array}$ & $\begin{array}{r}4.5943 \\
24.58^{* *}\end{array}$ \\
\hline JB Stat & $*$ & $*$ & $*$ & * & $*$ & $*$ & $*$ & $*$ & $*$ & $*$ & $*$ & * \\
\hline
\end{tabular}

Note: This table reports distributional properties of the VIX and VIX Futures in the period of 15 minutes before the announcement to 60 minutes after the announcement for non-announcement days and FOMC announcement days. We report mean, standard deviation, skewness, kurtosis, and the Jarque-Bera statistics for Normality of the distribution. We indicate significance at the $10 \%, 5 \%$, and $1 \%$ level by $*, * *$, and $* * *$, respectively. 
Table 4. The Impact of Changes Realized Volatilities on Changes in VIX

\begin{tabular}{|l|l|l|l|}
\hline & $\alpha$ & $\beta$ & $\mathrm{R}^{2}$ (adj) \\
\hline$\Delta \Delta$ VIX(1996-2013) & $-0.0105^{* * *}(-3.02)$ & $-2.733 * * *(-3.83)$ & $7.55 \%$ \\
\hline$\Delta \Delta$ VIX(2004-2013) & $-0.0115^{* *}(-2.23)$ & $-2.470 * * *(-3.53)$ & $6.80 \%$ \\
\hline$\Delta \Delta$ VIXF1 & $-0.0099 * * *(-3.79)$ & $-0.890^{* *}(-1.98)$ & $1.29 \%$ \\
\hline$\Delta \Delta$ VIXF2 & $-0.0059 * * *(-3.19)$ & $-0.556 * *(-2.26)$ & $0.79 \%$ \\
\hline$\Delta \Delta$ VIXF3 & $-0.0043 * * *(-3.20)$ & $-0.513 * *(-2.51)$ & $1.73 \%$ \\
\hline$\Delta \Delta$ VIXF4 & $-0.0032 * * *(-2.71)$ & $-0.451 * *(-1.99)$ & $1.97 \%$ \\
\hline
\end{tabular}

Note: This table reports the regression results for the regression of log changes in VIX and VIX futures on changes in realized volatility, i.e.

$$
\Delta \triangle V I X_{N}=\alpha+\beta \Delta R V_{N}+\varepsilon_{N},
$$

$\triangle \triangle V I X_{N}$ is the difference in the change in VIX over the window from 15 minutes before the FOMC announcement to 60 minutes after the FOMC announcement on announcement days versus non-announcement days, and $\Delta R V$ is the difference in the change in the realized volatility of the S\&P 500 index over the window from 15 minutes before the FOMC announcement to 60 minutes after the FOMC announcement on announcement days versus non-announcement days. We report Newey-West corrected t-statistics in parentheses, and indicate significance at the $5 \%$, and $1 \%$ level by $* *$, and $* * *$, respectively. 
Table 5. The Response of VIX to Surprises in the FOMC announcement

\begin{tabular}{|c|c|c|c|c|c|c|}
\hline & $\begin{array}{l}\text { VIX } \\
(1996-2013)\end{array}$ & $\begin{array}{l}V I X \\
(2004-2013) \\
\end{array}$ & VIX Fut $1^{s t}$ & VIX Fut $2^{\text {nd }}$ & VIX Fut $3^{r d}$ & VIX Fut $4^{\text {th }}$ \\
\hline \multirow{2}{*}{$\alpha_{0}$} & $-0.0137 * * *$ & $-0.0174 * * *$ & $-0.0124 * * *$ & $-0.0079 * * *$ & $-0.0056 * * *$ & $-0.0042 * * *$ \\
\hline & $(-2.71)$ & $(-2.69)$ & $(-3.86)$ & $(-3.51)$ & $(-3.61)$ & $(-3.46)$ \\
\hline \multirow{2}{*}{$\alpha_{1}$} & 0.0045 & 0.0057 & 0.0022 & -0.0018 & -0.0016 & -0.0029 \\
\hline & $(0.57)$ & $(0.31)$ & $(0.20)$ & $(-0.22)$ & $(-0.27)$ & $(-0.59)$ \\
\hline \multirow{2}{*}{$\beta_{1}$} & $-0.0203^{* * *}$ & -0.0848 & -0.0159 & 0.0674 & 0.0445 & 0.0611 \\
\hline & $(-4.61)$ & $(-0.42)$ & $(-0.13)$ & $(1.09)$ & $(0.89)$ & $(1.36)$ \\
\hline \multirow{2}{*}{$\alpha_{2}$} & $-0.0158 * *$ & -0.0118 & -0.0068 & -0.0007 & -0.0007 & -0.0003 \\
\hline & $(-2.00)$ & $(-1.04)$ & $(-0.76)$ & $(-0.12)$ & $(-0.18)$ & $(-0.10)$ \\
\hline \multirow{2}{*}{$\beta_{2}$} & $0.0260 * *$ & $0.0218 * * *$ & 0.0000 & 0.0031 & $0.0058 *$ & 0.0048 \\
\hline & $(2.37)$ & $(2.65)$ & $(0.00)$ & $(0.84)$ & $(1.81)$ & $(1.54)$ \\
\hline$R^{2}(a d j)$ & $10.10 \%$ & $3.26 \%$ & $-4.06 \%$ & $-3.69 \%$ & $-1.63 \%$ & $-1.04 \%$ \\
\hline
\end{tabular}

Note: This table reports the results for the regression of log changes in the VIX on the surprise in the FOMC announcement,

$$
\Delta V I X_{N}=\alpha_{0}+\left(\alpha_{1}+\beta_{1} S_{N}\right) D_{N}^{+}+\left(\alpha_{2}+\beta_{2} S_{N}\right) D_{N}^{-}+\varepsilon_{N}
$$

where $\triangle \mathrm{VIX}_{\mathrm{N}}$ is the change in the VIX in the period of 15 minutes before to 60 minutes after the FOMC announcement. $D_{N}^{+}$and $D_{N}^{-}$are dummy variables equal to 1 if the announcement carries a positive or negative surprise, respectively. $\mathrm{S}_{\mathrm{N}}$ measures the magnitude of the surprise in the announcement. The coefficient $\alpha_{0}$ captures the impact of FOMC announcement. The coefficients $\alpha_{1}$ and $\alpha_{2}$ capture the additional impact of a positive or negative surprise, respectively. The coefficients $\beta_{1}$ and $\beta_{2}$ capture the effect of the magnitude of positive and negative shocks, respectively. Newey-West corrected t-statistics are reported in parentheses and we indicate significance at the $10 \%, 5 \%$, and $1 \%$ level by *,**, and $* * *$, respectively. 
Table 6. Trading volume in VIX Futures

\begin{tabular}{|c|c|c|c|c|c|}
\hline & & \multicolumn{2}{|c|}{ Non-FOMC Announcement days } & \multicolumn{2}{|c|}{ FOMC Announcement Days } \\
\hline & & Mean & Median & Mean & Median \\
\hline \multirow{4}{*}{$1 \mathrm{st}$} & {$[-5: 0]$} & 98.04 & 11 & 117.96 & 19 \\
\hline & {$[0:+5]$} & 98.97 & 14 & 622.90 & 69 \\
\hline & Diff & 0.93 & 3 & $504.94 * * *$ & $50 * * *$ \\
\hline & T-Stat & 0.14 & 1.15 & 3.13 & -3.38 \\
\hline \multirow{3}{*}{ 2nd } & {$[-5: 0]$} & 68.66 & 5 & 61.53 & 7 \\
\hline & {$[0:+5]$} & 61.39 & 5 & 359.37 & 43 \\
\hline & Diff & 7.26 & 0 & $297.84 * * *$ & $36 * * *$ \\
\hline \multirow{5}{*}{$3 \mathrm{rd}$} & T-Stat & 1.60 & 0.18 & 3.31 & 3.12 \\
\hline & {$[-5: 0]$} & 25.63 & 1 & 34.09 & 2 \\
\hline & {$[0:+5]$} & 24.14 & 1 & 149.84 & 23 \\
\hline & Diff & 1.49 & 0 & $115.75 * * *$ & $21 * * *$ \\
\hline & $T$-Stat & 0.80 & 0.44 & 3.06 & 2.84 \\
\hline \multirow{4}{*}{4 th } & {$[-5: 0]$} & 15.59 & 0 & 21.64 & 2 \\
\hline & {$[0:+5]$} & 16.69 & 0 & 97.55 & 7 \\
\hline & Diff & -1.1 & 0 & $75.91 * * *$ & $5^{* *}$ \\
\hline & $T$-Stat & 0.79 & 1.07 & -2.85 & 2.13 \\
\hline
\end{tabular}

Note: This table reports average trading volume in the VIX Futures around the time of the FOMC announcement on announcement versus non-announcement days. We report the mean and median trading volume in the interval of 5 minutes before the announcement to the exact announcement time, and the interval of the announcement time to 5 minutes after the announcement. We perform a t-test to assess whether average trading volume is significantly different in the period leading up to the announcement and the period after, and a Wilcoxon rank test to assess whether median trading volume is significantly different. We indicate significance at the $10 \%, 5 \%$, and $1 \%$ level by $* * *$, and $* * *$, respectively. 
Table 7. Trading Strategy in the VIX Futures

\begin{tabular}{|c|c|c|c|c|c|c|c|c|}
\hline \multicolumn{9}{|c|}{ Panel A: Full Sample } \\
\hline & \multicolumn{4}{|c|}{ Non-Announcement days } & \multicolumn{4}{|c|}{ FOMC Announcement days } \\
\hline & $1 \mathrm{st}$ & 2nd & $3 \mathrm{rd}$ & 4 th & $1 \mathrm{st}$ & 2nd & $3 \mathrm{rd}$ & 4th \\
\hline \multicolumn{9}{|c|}{ Excess returns } \\
\hline Average & $-0.0075 * * *$ & $-0.0085^{* * *}$ & $-0.0093 * * *$ & $-0.0102 * * *$ & $0.0125 * * *$ & $0.0056^{*}$ & 0.0019 & -0.0014 \\
\hline & $(-11.29)$ & $(-17.57)$ & $(-22.75)$ & $(-25.71)$ & $(3.25)$ & $(1.91)$ & $(0.82)$ & $(-0.63)$ \\
\hline Daily geometric mean & -0.0081 & -0.0088 & -0.0095 & -0.0104 & 0.0119 & 0.0053 & 0.0017 & -0.0015 \\
\hline \multicolumn{9}{|c|}{ Risk measures } \\
\hline Volatility & 0.0324 & 0.0236 & 0.0197 & 0.0187 & 0.0339 & 0.0260 & 0.0205 & 0.0185 \\
\hline Downside volatility $(<0)$ & 0.0257 & 0.0188 & 0.0157 & 0.0160 & 0.0130 & 0.0098 & 0.0091 & 0.0110 \\
\hline Skewness & -0.7049 & -0.8317 & -0.6344 & -1.5147 & 1.5154 & 1.1020 & 1.0313 & 0.5475 \\
\hline Kurtosis & 7.9812 & 8.4250 & 5.7433 & 13.3303 & 8.1612 & 5.1511 & 4.9284 & 4.6784 \\
\hline 99\% VaR (Cornish-Fisher) & 0.1312 & 0.1018 & 0.0741 & 0.1037 & 0.0402 & 0.0350 & 0.0313 & 0.0422 \\
\hline$\%$ of positive days & $41 \%$ & $33 \%$ & $29 \%$ & $27 \%$ & $67 \%$ & $59 \%$ & $45 \%$ & $43 \%$ \\
\hline \multicolumn{9}{|c|}{ Risk-adjusted performance } \\
\hline Sharpe ratio & -0.2325 & -0.3615 & -0.4690 & -0.5441 & 0.3681 & 0.2167 & 0.0932 & -0.0729 \\
\hline Sortino ratio $(0 \%)$ & -0.2658 & -0.3808 & -0.4623 & -0.5040 & 0.9416 & 0.4509 & 0.1682 & -0.1046 \\
\hline Omega ratio $(0 \%)$ & 0.5180 & 0.3603 & 0.2712 & 0.2010 & 2.9617 & 1.8088 & 1.2800 & 0.8210 \\
\hline
\end{tabular}


Table 7 (continued)

\begin{tabular}{|c|c|c|c|c|c|c|c|c|}
\hline \multicolumn{9}{|c|}{ Panel B: January 2008 - December 2013} \\
\hline & \multicolumn{4}{|c|}{ Non-announcement days } & \multicolumn{4}{|c|}{ Fed Fund announcement days } \\
\hline & $1 \mathrm{st}$ & 2nd & $3 r d$ & 4th & $1 \mathrm{st}$ & 2nd & $3 \mathrm{rd}$ & 4th \\
\hline \multicolumn{9}{|c|}{ Excess returns } \\
\hline Daily arithmetic mean & $-0.0055^{* * *}$ & $-0.0064 * * *$ & $-0.0071 * * *$ & $-0.0082 * * *$ & $0.0114 * * *$ & $0.0065 *$ & 0.0025 & -0.0001 \\
\hline t-stat & $(-6.11)$ & $(-9.65)$ & $(-12.77)$ & $(-15.82)$ & $(2.74)$ & $(1.91)$ & $(0.88)$ & $(-0.05)$ \\
\hline Daily geometric mean & -0.0061 & -0.0067 & -0.0073 & -0.0084 & 0.0110 & 0.0063 & 0.0023 & -0.0003 \\
\hline \multicolumn{9}{|c|}{ Risk measures } \\
\hline Daily volatility & 0.0344 & 0.0254 & 0.0212 & 0.0198 & 0.0289 & 0.0237 & 0.0200 & 0.0190 \\
\hline Daily downside volatility $(<0)$ & 0.0273 & 0.0201 & 0.0168 & 0.0170 & 0.0118 & 0.0078 & 0.0082 & 0.0120 \\
\hline Skewness & -0.7225 & -0.6755 & -0.6215 & -1.2059 & 0.5062 & 0.6723 & 0.7283 & 0.3577 \\
\hline Kurtosis & 5.2602 & 5.2842 & 4.7307 & 7.9729 & 3.4667 & 3.9178 & 3.9747 & 4.7631 \\
\hline 99\% VaR (Cornish-Fisher) & 0.1152 & 0.0872 & 0.0717 & 0.0838 & 0.0454 & 0.0380 & 0.0338 & 0.0463 \\
\hline$\%$ of positive days & $48 \%$ & $41 \%$ & $38 \%$ & $35 \%$ & $69 \%$ & $67 \%$ & $54 \%$ & $50 \%$ \\
\hline \multicolumn{9}{|c|}{ Risk-adjusted performance } \\
\hline Sharpe ratio & -0.1605 & -0.2527 & -0.3343 & -0.4141 & 0.3950 & 0.2758 & 0.1265 & -0.0075 \\
\hline Sortino ratio $(0 \%)$ & -0.1894 & -0.2828 & -0.3555 & -0.4108 & 0.8779 & 0.5506 & 0.2221 & -0.0110 \\
\hline Omega ratio $(0 \%)$ & 0.6438 & 0.4985 & 0.3989 & 0.2983 & 2.8014 & 2.0252 & 1.3733 & 0.9798 \\
\hline
\end{tabular}

Note: This table reports results on the profitability of a trading strategy in the VIX futures, where a short position is taken at the prevailing bid quote at 9.35 EST and a long position is taken at $15.30 \mathrm{EST}$, we also incorporate a transaction cost of $0.1 \%$ per trade. We compare the performance of the trading strategy on days with and without FOMC announcements and report statistics on daily returns, risk measures and risk-adjusted performance. T-statistics are reported in parentheses and we indicate significance at the $10 \%, 5 \%$, and $1 \%$ level by $*$, **, and $* * *$, respectively. 
Figure 1. Distribution of the Difference between Actual and Scheduled Announcement Times

\section{Precision}

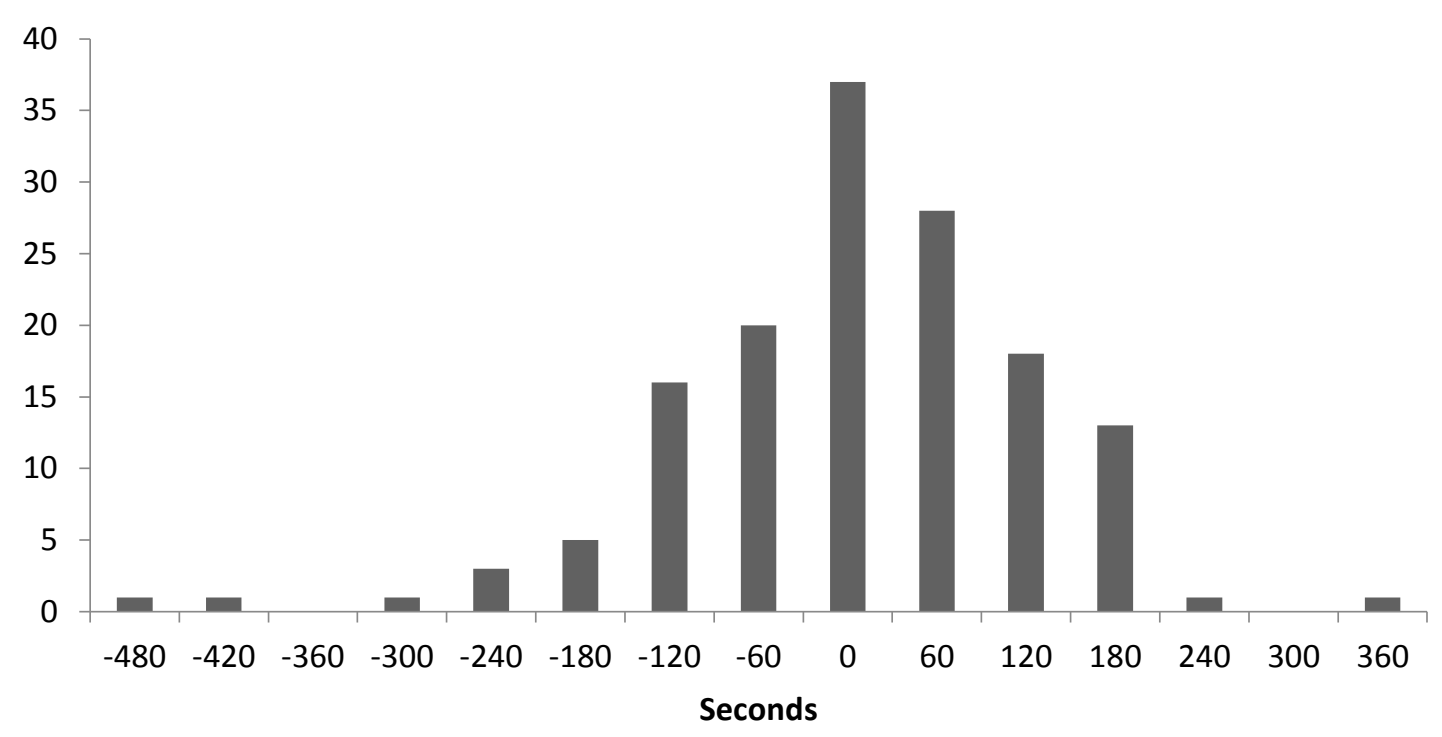

Note: This figure shows the difference between the actual and the scheduled FOMC announcement time. The difference is reported in seconds on the $\mathrm{x}$-axis. 
Figure 2. Cumulative Change in the VIX on FOMC versus Non-Announcement Days

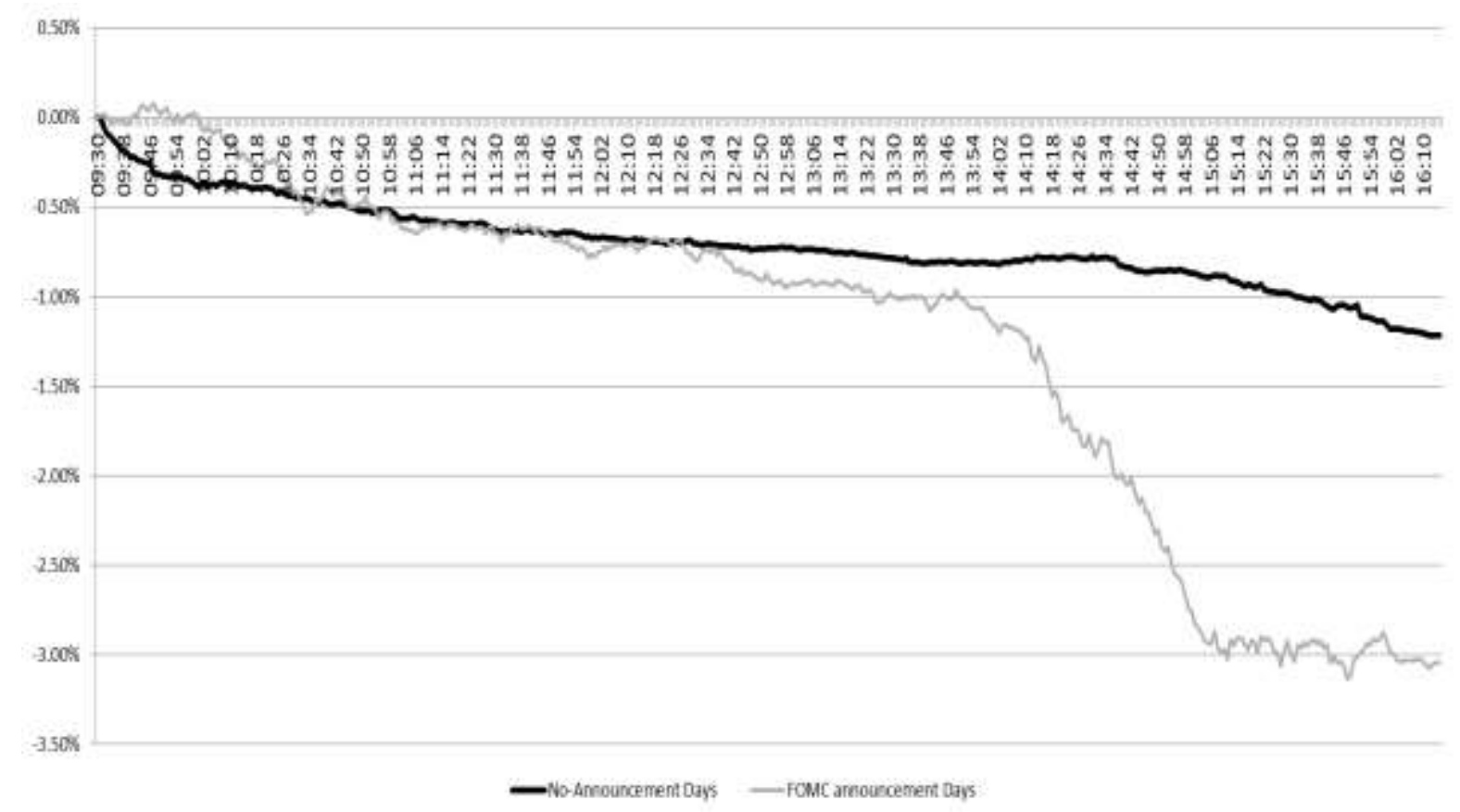

Note: This figure plots the evolution at a one-minute frequency of the VIX during non-announcement days (black line) and announcement days (grey line). 
Figure 3. Cumulative Change in the VIX and VIX futures around FOMC Announcement Times

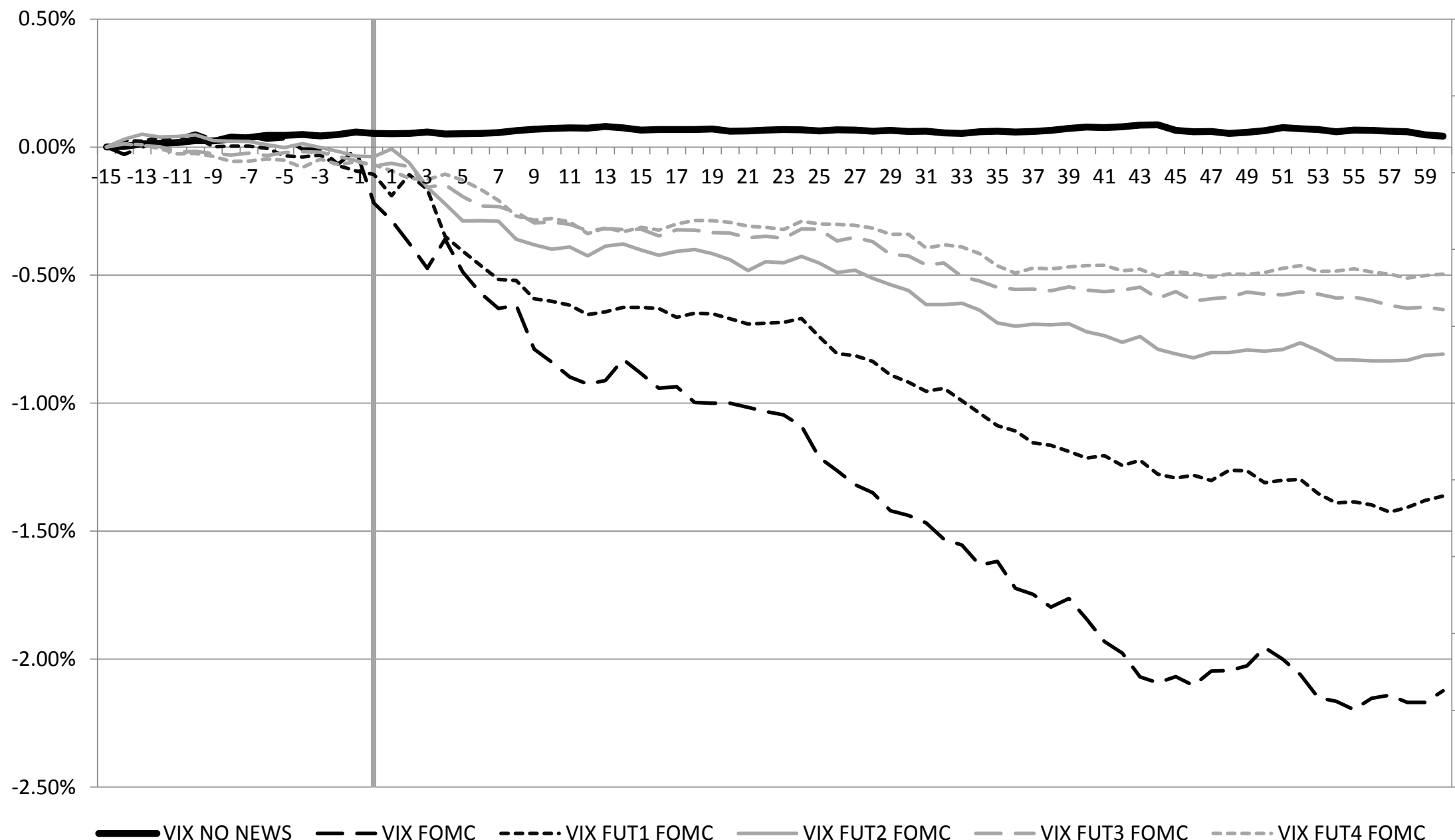

Note: This figure plots the evolution at a one-minute frequency of the VIX on announcement and non-announcement days and the VIX futures on announcement days over the interval from 15 minutes before the FOMC announcement to 60 minutes after the FOMC announcement. 
Figure 4. Reaction of VIX Futures to FOMC Announcements

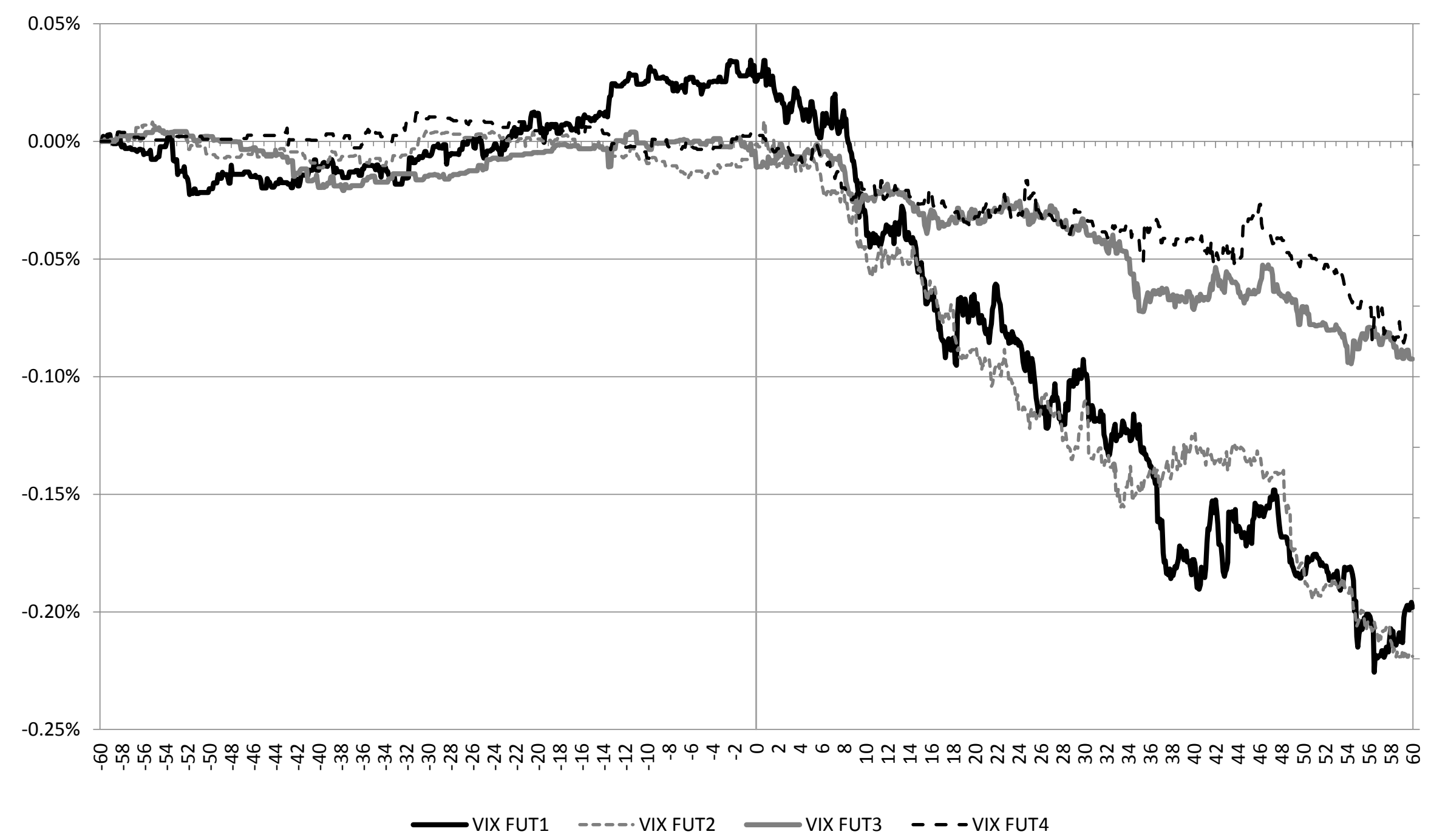

Note: This figure plots the evolution at a decisecond frequency of the VIX Futures over the interval from 1 minute before the FOMC announcement to 1 minute after. 
Figure 5. 30-Second Rolling Average of VIX Futures Trading Volume

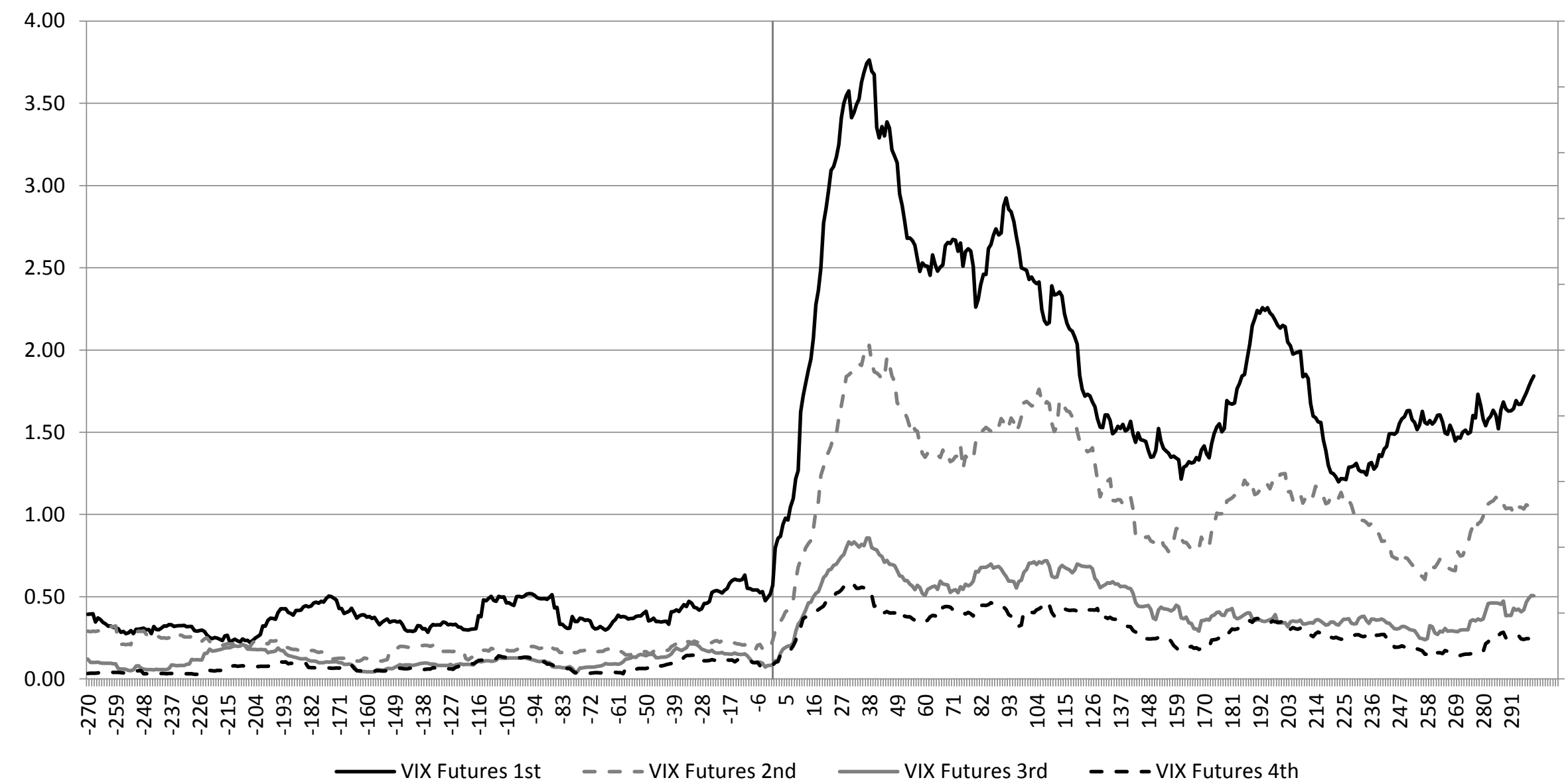

Note: This figure plots a 30-second rolling-window of trading volume in the VIX futures contracts in the period of 5 minutes before to 5 minutes after the FOMC announcement. 